\title{
(2)
}

José Miguel Andreu*

\section{LÍMITES FUNCIONALES DEL CAPITALISMO EN EL SIGLO XXI El problema distributivo y la sostenibilidad democrática}

En relación con los múltiples cambios económicos acaecidos en el siglo XX -algunos de ellos con capacidades para inducir la inestabilidad o insostenibilidad de la actual combinación capitalismo-democracia- el artículo se refiere extensamente a la evolución de la distribución personal de la renta y la riqueza en los últimos dos siglos, a la luz de los nuevos datos aportados por el profesor Piketty. Datos que, como se verá, permiten proyectar lo que podría suceder en el siglo XXI.

El artículo, siguiendo a Piketty, discute las pretendidas tendencias «naturales» hacia la concentración versus la desconcentración del capital y de la renta, defendidas respectivamente por Marx y Kuznets en los siglos XIX y Xx; discusión realizada por Piketty sobre la base de la evidencia empírica de los últimos dos siglos.

Tras un planteamiento matemático sencillo, Piketty afirma que el diferencial entre la tasa de rendimiento del capital y la tasa de crecimiento de la economía $(r-g)$ es el determinante básico de la tendencia subyacente del capitalismo hacia la concentración de la riqueza y la renta; evolución que, sin embargo, a veces -en periodos de guerra, crisis económicas o mutaciones fiscales- ha cambiado de sentido. De resultas de los problemas socio-políticos derivados de la mencionada tendencia subyacente, Piketty sugiere como solución la introducción de una imposición anual y progresiva sobre el capital, que desactive la tendencia hacia su concentración en pocas manos.

Palabras clave: sostenibilidad, capitalismo-democracia, diferencial $r$ - $g$; sociedades hipermeritocráticas, flujos sucesorios, crecimiento y distribución, nueva clase patrimonial, impuesto anual y progresivo sobre el capital neto.

Clasificación JEL: D30, D72, O15, P30.

\section{Introducción}

En relación con los cambios distributivos de la riqueza y la renta registrados a lo largo de los siglos XIX y Xx en buena parte del mundo occidental y en otros países, este artículo analiza en primer

* Catedrático de Teoría Económica.

Versión de febrero de 2015. término los hallazgos empíricos de Piketty derivados de su investigación sobre la materia.

Como quiera que una adecuada distribución personal de la renta y la riqueza será relevante para potenciar el crecimiento económico, pero también para ganar en seguridad y sostenibilidad democráticas, el artículo sostiene que aunque el capitalismo contenga unas tendencias subyacentes hacia la concentración del capital, la política $\triangleright$ 
económica (fiscal) podrá corregir esas tendencias, para así garantizar la sostenibilidad democrática.

Tras describir la causa básica de la tendencia a la concentración del capital -esto es, el diferencial $r$ - $g$ ya mencionado ${ }^{1}$ - el artículo también describe por separado las tendencias recientes hacia la concentración de las rentas procedentes de los salarios, debidas a la aparición de las equívocamente denominadas «sociedades meritocráticas" y de los "superejecutivos»; y hacia la desconcentración relativa de la riqueza y de las rentas procedentes del capital, en función, respectivamente, de la aparición reciente de las llamadas clases medias patrimoniales y de los superejecutivos. El artículo termina con las recomendaciones fiscales de Piketty, en particular la del establecimiento de un impuesto progresivo anual sobre el capital que, siendo hoy por hoy difícil de implementar, está sin embargo en el centro de las discusiones políticas y académicas al respecto, particularmente en EEUU.

\section{Cambios económicos en el siglo xx: crecimiento y distribución}

Desde la Revolución francesa hasta hoy, alcanzar la combinación óptima de democracia con máximo crecimiento económico no ha sido una tarea fácil. Ello se ha debido a la existencia de un difícil equilibrio entre el crecimiento económico eficiente -siempre necesitado de ciertas desigualdades individuales que fomenten el estímulo a la adopción de decisiones económicas arriesgadas-y la democracia, sistema político intrínsecamente proclive a soluciones más igualitarias. Como consecuencia de ese equilibrio, a veces precario, muchas de las democracias nacientes en los últimos siglos -incluyendo la francesa, nacida en 1789- desaparecieron poco después de su nacimiento. Pero el mundo ha

1 Diferencial $r$ - $g$ entre la tasa de rendimiento del capital $r$ y la tasa de crecimiento de la economía $g$. cambiado mucho desde entonces, sobre todo en los últimos 30 años.

A fin de aproximarnos a la velocidad reciente del cambio económico-político habido, podríamos fijar nuestra atención en la aceleración geométrica registrada en los últimos tiempos por ciertas variables actuantes en esos ámbitos. Particularmente arraigados en nuestra memoria se encuentran los grandes cambios económicos producidos en las últimas décadas, en las que, tras el crecimiento acelerado experimentado por Occidente y Europa en la llamada edad de oro del capitalismo (1950-1973), Occidente, y particularmente Europa, han entrado en una etapa de decadencia relativa. Decadencia derivada, entre otras causas, de la madurez económica ya alcanzada, y de la implementación de la última etapa del proceso de globalización -la liberalización de los movimientos de capitales ${ }^{2}-$ que, inopinadamente, está desplazando el centro económico de gravedad hacia Asia, lo que al mismo tiempo ha posibilitado el inicio de la llamada Gran Convergencia. Fenómeno que ha hecho que algunos países extra-occidentales crezcan a más velocidad que Occidente en su conjunto.

A la hora de evaluar lo sucedido en los últimos siglos con una cierta perspectiva, convendría recordar el perfil real del fenómeno del crecimiento a escala planetaria desde el inicio de la Revolución Industrial. Ciertamente, aunque la tasa de crecimiento de la producción del planeta en los últimos 3 siglos haya sido de media el 1,6 por $100(0,8$ por 100 en términos del PIB per cápita $)^{3}$, desde el inicio de la Revolución Industrial hasta el periodo entre guerras del siglo $\mathrm{xx}$, la tasa de crecimiento del PIB mundial fue bastante más moderada (como del 1 por 100 de media anual).

\footnotetext{
2 Tal liberalización ha sido asimétrica y ha tenido lugar más bien en Occidente, dado que bastantes países en desarrollo todavía seleccionan los sectores en los que los capitales extranjeros pueden entrar, al tiempo que condicionan las inversiones realizadas por sus nacionales en el extranjero.

3 Nótese que esa tasa de crecimiento del PIB per cápita del 0,8 por 100 sólo permite duplicar el nivel de vida cada 90 años.
} 
Posteriormente cuando, tras la Segunda Guerra Mundial, empezó la reconstrucción europea, la tasa de crecimiento del planeta se expandió durante más de dos décadas (1950-1973, a lo largo de la edad de oro del capitalismo) a una tasa media de en torno al 2 por 100; tasa resultante de la rápida velocidad expansiva de Occidente en esos años y de los pobres resultados económicos de la etapa postcolonial en muchos lugares del mundo. Sin embargo, en la segunda mitad de los años setenta del siglo $\mathrm{xx}$, esa tasa de crecimiento global se moderó a causa de las crisis energéticas de 1973 y 1979 para, después, acelerarse en las últimas tres décadas (1980-2010) en las que el $\mathrm{PIB}$ mundial ha crecido a un ritmo medio del 2,5 por 100; tasa más alta que la registrada en décadas anteriores, debida sobre todo al fenómeno de convergencia económica iniciada por los países emergentes y otros países en desarrollo. En este sentido no debería perderse de vista que en esas tres décadas (1980-2010) Occidente, y sobre todo Europa, han experimentado tasas medias evolutivas bastante menores que la media mundial (2,5 por 100), mientras el mundo emergente y en desarrollo crecía a tasas medias mucho mayores, como del 4,5 por $100^{4}$.

Por consiguiente, las sociedades occidentales, y sobre sobre todo las europeas que todavía continúan con su «nostalgia de crecimiento rápido», deberían hacer un esfuerzo de adaptación a las nuevas expectativas de crecimiento en el siglo $x X I$, en el que tan solo son esperables ritmos de crecimiento moderados y paulatinamente decrecientes a escala planetaria, que podrían llegar a ser como del 1,5 por 100 al final del periodo.

Ha de subrayarse, por tanto, que el crecimiento económico, fenómeno de reciente visibilidad y objetivo máximo de las actuales democracias nacionales, ha mostrado un perfil bastante diferenciado en los siglos XIX y XX; y además con importantes divergencias entre los distintos países occidentales

\footnotetext{
4 Esa tasa del 4,5 por 100 es una media de los ritmos de crecimiento de los países de ingreso medio y bajo en las últimas tres décadas, obtenida a partir de las cifras del Banco Mundial (2013) en World Development Indicators.
}

actuantes ${ }^{5}$; pero, sobre todo, con un cambio de marchas apreciable en las últimas décadas (19802010), entre la moderada o débil velocidad de progresión de los países más desarrollados (occidentales), y la más alta de los hoy denominados países emergentes y en desarrollo, en particular China y a una cierta distancia, India.

Nótese que el último cambio de filosofía económica acaecido en el mundo occidental, la llamada Revolución Conservadora iniciada en 1975-1980, proclive a una vuelta a los principios básicos, esto es, a una mayor libertad de los agentes privados actuantes y a un menor control social de la acciones económicas emprendidas, ha generado dos fenómenos extremadamente importantes y diversos: 1) una convergencia económica significativa entre las principales naciones actuantes, lo que ha venido reduciendo el gap económico relativo (de PIB per cápita) de muchos de los países anteriormente atrasados; y 2) un empeoramiento generalizado, esto es, una más intensa concentración de la distribución personal de la renta y del capital, a escala interna de los distintos países, incluyendo los más relevantes de Occidente (EEUU, RU, algunos de la eurozona, etcétera).

Ahora bien, la sostenibilidad democrática no depende exclusivamente de la distribución de la renta o de la riqueza a escala interna de cada país. Nótese que las democracias establecidas hasta hoy, de carácter exclusivamente (o básicamente) nacional, y por tanto de carácter fragmentario a escala mundial, no parecen poder atender, ni de lejos, a los requerimientos actuales de la sociedad global ${ }^{6}$. Una sociedad que reclama la resolución $\triangleright$

\footnotetext{
5 A partir de los años 1975-1980 la tendencia anterior se invirtió, con ritmos de crecimiento más rápido en Europa Continental que en EEUU, RU y otros países de inmigración anglosajona; y en Europa, junto a una cierta decadencia económica, comenzó a sentirse una cierta nostalgia (cada vez más acentuada) por un pasado económico brillante que, al haber contenido una importante actividad de reconstrucción, no será replicable, en ausencia de guerras, en las próximas décadas.

6 La sociedad global está formada por todos los países (193) pertenecientes a la ONU. En Occidente, sin embargo, suele aludirse constantemente a la llamada comunidad internacional, subconjunto de la sociedad global formado básicamente por los países ricos (EEUU, UE, OTAN, OCDE, etcétera).
} 
de los nuevos problemas económicos aparecidos o detectados, relacionados con la provisión de bienes públicos globales, con la corrección de las externalidades globales, y con la información y el control sobre los monopolios, el comercio y las inversiones financieras internacionales.

\section{Fuentes de no sostenibilidad de la actual combinación capitalismo-democracia}

Como ha quedado probado en muchos lugares a lo largo de buena parte de la segunda mitad del siglo $\mathrm{XX}$, las democracias «informadas» ${ }^{7}$ se configuran como el único sistema de gobierno capaz de alcanzar simultáneamente los objetivos de producción doméstica eficiente a largo plazo, y de distribución aceptable de las rentas y del capital.

Ahora bien, la segunda mitad del siglo xx también ha probado reiteradamente que los Estados nacionales no pueden resolver por sí solos los problemas económicos que rebasan el ámbito de su jurisdicción, sean estos de carácter distributivo o tengan que ver con otros fenómenos que afectan a la sociedad global. Me refiero a la provisión de bienes públicos globales, a la corrección de las externalidades globales, al control de los monopolios o carteles internacionales, etcétera, que a todos nos afectan.

A este respecto, ha de subrayarse que la actual fórmula de gobernación global o supranacional sui generis $^{8}$, dimanante de los resultados de la Segunda Guerra Mundial (ONU, BM, FMI, etcétera), hoy ya muy desgastada e inadaptada a los cambios político-estructurales habidos (globalización), no solo es política y económicamente ineficiente para el conjunto de la sociedad global, incluyendo la occidental, sino que, a veces, se sitúa en contradicción con el reiterado objetivo occidental de promoción incondicional de la democracia.

\footnotetext{
7 Democracias «informadas» son aquellas en las que habiendo desaparecido el analfabetismo en las sociedades en que se sustentan, casi todos los individuos adultos conocen suficientemente los problemas del país y los diversos modos individuales o colectivos de solucionarlos.

8 En relación con la provisión de bienes públicos globales o en conexión con la corrección de externalidades globales.
}

Como resultado de la aparición en escena o de la consideración primigenia de los nuevos problemas económicos globales, más otros ya tradicionales como los derivados de la existencia de windfalls $s^{9}$, a los que se ha añadido la reaparición a partir de los años ochenta de un grave problema que Occidente ${ }^{10}$ creía haber encauzado después de las dos últimas guerras mundiales -la distribución interna de la renta y la riqueza-, el sistema capitalista está comenzando de nuevo a parecer a muchos analistas como «no sostenible» a largo plazo. Y ello por diferentes razones: 1) porque el capitalismo que, en sus diferentes aproximaciones ${ }^{11}$, ha ganado mucho terreno a lo largo y ancho del mundo, transformándose en global, carece sin embargo de una infraestructura política (global) que, legítimamente, ejerza el control (democrático) de la actividad económica global desarrollada por un sector privado que, en la práctica, ejerce sus actividades «sin límites» políticos;2) porque ese capitalismo global, al haber degradado en los últimos 30 años en casi todo el mundo (occidental) la distribución personal de la renta y la riqueza, no garantiza ya a largo plazo ni la estabilidad social ni la sostenibilidad democrática ${ }^{12}$; 3) porque las versiones más radicales del capitalismo, de nuevo en auge en el periodo 1980-2010, con su peligrosa tendencia hacia una casi exclusiva orientación hacia el mercado, particularmente en el mundo laboral ${ }^{13}$, están poniendo en riesgo los $\triangleright$

\footnotetext{
9 Los windfalls (bienes que caen como del aire, esto es sin esfuerzo significativo) se refieren a la producción o extracción de materias primas escasas y muy valiosas a nivel mundial, como son el petróleo, el gas, los diamantes, y el oro.

10 En el conjunto del mundo, la distribución empeoró, en perjuicio de los países en desarrollo, desde la Revolución Industrial hasta hace unos pocos años; esto es, hasta que empezó la última etapa de la globalización: «la liberalización de los movimientos de capitales», que ha actuado como dinamizador de la reasignación geográfica y sectorial de los recursos.

11 Lo que hoy se denomina genéricamente como capitalismo, incluye dentro de sí importantes variantes que van desde sus versiones más radicales en las que el mercado lo inunda todo y el estado de bienestar no adquiere más que formas incipientes o irrelevantes en sanidad, educación, pensiones, etcétera, hasta las versiones más suaves del mismo, como las de los llamados países nórdicos (del norte de Europa), en los que al lado del mercado libre, el sector público mantiene un rol preponderante en la provisión de bienes y servicios públicos.

12 Como tampoco las garantizaba en muchos lugares de Europa Occidental en el último tercio del siglo XIX y principios del XX.

13 Como si el trabajo humano fuera una mercancía no esencial.
} 
fundamentos básicos de la sociedad, incluyendo la familia; y 4) porque la progresiva degradación del medio ambiente y la extinción de algunos recursos no renovables, inducidos por el crecimiento demográfico, y por el consumo exagerado, están poniendo en riesgo la sostenibilidad del sistema físico-ambiental del planeta.

\section{La distribución personal de la renta y la riqueza para ganar en seguridad y sostenibilidad democrática}

Aunque son diversas las variables que podrían poner en peligro la sostenibilidad democrática en las próximas décadas, en las líneas siguientes nos centraremos en el problema distributivo, que está adquiriendo en nuestros días un tono un tanto dramático.

Afortunadamente, tras dos catástrofes materiales y humanas (Primera y Segunda Guerra Mundial) y tras la crisis de 1929, los Gobiernos europeos occidentales aprendieron algunas lecciones de la historia, y en 1945 comenzaron la construcción ${ }^{14}$ en sus territorios del llamado estado de bienestar. Los costes sociales y humanos en los que se había incurrido desde el último tercio del siglo XIX, derivados de la constante agitación social y de las guerras contra países vecinos, habían sido muy altos y no podían continuar tras la Segunda Guerra Mundial. Con el establecimiento o la ampliación del estado de bienestar el escenario social cambió muy positivamente; aunque lamentablemente, casi exclusivamente en Europa Occidental.

Sin embargo, «la falta de memoria» de los Gobiernos europeos occidentales (y de otros) hizo que algunas décadas después, a partir de 1980, la miopía social, practicada en Occidente desde los inicios de la Revolución Industrial, comenzara de nuevo a afectar a Europa. De hecho, y a pesar de los efectos positivos de la construcción del estado de bienestar sobre la paz y la seguridad internas y sobre la prosperidad económica

14 O la ampliación del preexistente estado (incipiente) de bienestar. de Europa, las últimas tres décadas (1980-2010) han sido testigos de la reaparición de las viejas tendencias ${ }^{15}$, materializadas en la degradación de la distribución personal de la renta (y en la concentración adicional de patrimonios), y en el visible deterioro económico de buena parte de las clases medias ${ }^{16}$ y populares. Y ello por no mencionar el rápido deterioro medioambiental, la sostenida agresividad de los monopolios internacionales, e inclusive, la reciente reanudación encubierta de la guerra fría, generadora de incertidumbre.

\subsection{Capitalismo y equidad mínima para su aceptación}

En un entramado capitalista puramente competitivo, esto es sin intervención significativa del sector público, se producirá una tendencia automática hacia la concentración de la renta y la riqueza. Esta es la razón por la que tal automatismo, no deseable en tanto que es generador de inestabilidad social y política, debería ser compensado en opinión de muchos, incluyendo a Piketty, con una política de redistribución pública (impuestos progresivos sobre la renta, el capital, y las herencias, en combinación con otras políticas de gasto social: educación, sanidad, pensiones, etcétera), y de transferencias específicas a ciertos grupos económicamente modestos. Ciertamente, solo esa política de redistribución hará que el capitalismo sea aceptable por todos aquellos que al nacer ${ }^{17}$ apenas recibieron algo, frente a aquellos otros que a su nacimiento heredaron una $D$

\footnotetext{
${ }^{15}$ El mismo comentario podría hacerse en relación con EEUU. De hecho, durante los años cincuenta y sesenta, los mejores años de la clase media en EEUU, la productividad del país creció, los beneficios del crecimiento se repartieron adecuadamente entre rentistas y trabajadores, y el gap entre las grandes rentas y los menores salarios se estrechó. Sin embargo, algunos años después, a partir de 1980, el gap de rentas entre ricos y pobres comenzó a ensancharse hasta alcanzar un nuevo máximo relativo en nuestros días.

16 Nótese que las clases medias no existían en ninguna parte del mundo durante el siglo XIX. Tampoco antes.

17 Nótese que nada menos que el 50 por 100 de la población menos favorecida en cualquier país del mundo occidental (y en el resto del mundo) apenas tiene capital acumulado alguno que transferir a sus descendientes.
} 
expectativa de acceso a capitales importantes, sin la realización de esfuerzo alguno.

En la medida en que la distribución inicial de activos entre los individuos sea tomada como un mero dato por el modelo puramente competitivo en el que se sustenta el capitalismo más radical, la democracia, siempre proclive a la distribución, deberá no solo mantener o fomentar los esquemas competitivos para ganar en eficiencia, sino también diseñar un sistema redistributivo suficiente como para evitar que los más desfavorecidos, que tienden a conformar de modo natural las mayorías políticas, tengan la tentación de abrir la «caja de Pandora» distributiva; caja que contiene en todos los países la historia de la desagradable y, a veces sangrienta ${ }^{18}$, distribución personal de la renta y riqueza actuales. Nótese al respecto que si la mayoría política no encontrara justicia económica en la democracia establecida, trataría de cambiar el sistema abriendo de nuevo esa caja de Pandora. Por ello, los Gobiernos democráticos, huyendo de cualquier extremismo, siempre deberán compensar los déficits aceptables que un sistema capitalista puro siempre inducirá a largo plazo.

\subsection{Transferencias o reasignaciones a los más desfavorecidos para garantizar la estabilidad democrática}

\section{Desde hace décadas existe un consenso ge-} neral que señala que un sistema que promueva una distribución igualitaria total no puede funcionar en el contexto de una economía moderna, diversificada e interactiva. Conclusión a la que se ha llegado porque un sistema socialista tendente a la igualación de rentas (el llamado socialismo real) propende a destruir los incentivos individuales en

\footnotetext{
18 Ludwig Von Mises, reconocido economista neoclásico de la Escuela Austriaca, declaró en su libro Socialismo (1951), que «toda propiedad deriva de la ocupación o la violencia previas». Lo que, sin embargo, no es del todo exacto porque también hay propiedades (pequeñas) que derivan del ahorro previo sobre rentas procedentes del trabajo.
}

los campos de la educación, el ahorro, las inversiones, así como en el laboral, al tiempo que resulta incompatible con la existencia de cualquier organización humana jerarquizada, necesaria para alcanzar una mínima eficiencia productiva.

Paralela, aunque contrariamente, el capitalismo en sus versiones más puras (con sector público pequeño y sin estado de bienestar), aunque competitivo (y supuestamente eficiente), no conducirá ni a una distribución del ingreso aceptable para una gran mayoría de la población, ni a la sostenibilidad de la democracia ${ }^{19}$ y 20 . Frente a esas dos posiciones polares, socialismo y capitalismo extremados, los Estados capitalistas moderados, gestionados por partidos políticos templados o diversas formas de social-democracia, y sustentadores de las economías mixtas de mercado, conducirán a distribuciones del ingreso y del capital que, corregidas con impuestos progresivos y adecuados sistemas de bienestar (educación, sanidad, pensiones, etcétera), generarán prosperidad económica y democracias sostenibles.

Como se dice en todos los manuales de ciencia política, la realización de algunas formas de reasignación económica desde el Estado a los individuos (como las transferencias a los más desfavorecidos) será inevitable, incluso en aquellos sistemas capitalistas con sectores públicos escasamente dimensionados. Nótese adicionalmente que en las llamadas economías mixtas de mercado $^{21}$, con amplio sector público (esto es, con una participación del sector público en la actividad, como del 35-50 por 100 en el PIB), siempre habrá un cierto margen para la reasignación de ingresos sin incurrir en riesgos políticos significativos. Como consecuencia de lo anterior, cuanto $D$

\footnotetext{
19 Como veremos más adelante, si la tasa real neta de rendimiento del capital $r$ supera al ritmo de crecimiento real de la producción $g$, el proceso de concentración del capital y de la renta será automático, ceteris paribus.

20 Nótese asimismo que un sistema capitalista, con mercados libres, puede generar precios y salarios considerados como injustos por una mayoría de los votantes; particularmente en casos de distribución injusta de la propiedad (herencias acumuladas indefinidamente), de gobernación deficiente, y de altos grados de monopolio o monopsonio.

21 O economías sociales de mercado.
} 
mayor sea la clase media, derivada de la existencia de un sector privado diversificado, bien dimensionado y competitivo, y de una apreciable y estable función pública ${ }^{22}$, menor relevancia cuantitativa tendrán las reasignaciones públicas de ingresos a los más modestos; y por consiguiente menor será el número de individuos afectados positiva o negativamente por el proceso democrático de alternancia en el poder, lo que protegerá la «aceptabilidad» del sistema democrático vigente.

\subsection{Relevancia de la propiedad privada para la sostenibilidad de la democracia}

Se ha dicho muchas veces, sobre todo en tiempos del liberalismo tradicional del siglo XIX y principios del xx, que el capitalismo solo será coherente con la democracia cuando el Gobierno garantice totalmente la inviolabilidad de la propiedad privada. En mi opinión, sin embargo, esa afirmación tan tajante es incorrecta. Obsérvese que si la renta, que permite consumir o ahorrar -ahorro que, por acumulación, generará propiedad o riqueza- puede ser objeto de imposición progresiva, es decir de reasignación pública de ingre$\operatorname{sos}^{23}$, los activos o el capital existente, derivados de la sucesión de rentas ahorradas, también deberán serlo, bien para completar democráticamente la progresividad (del sistema fiscal corriente), o bien para expropiar determinados bienes, previa compensación económica.

En ese sentido, en función de la posible existencia de monopolios industriales o comerciales abusivos, de propiedades agrarias ineficientes, o a causa de la tendencia automática a la sobreacumulación de riqueza por un limitado grupo de individuos (ricos o muy ricos) -que suelen intentar

22 Siempre que el acceso a la función pública haya sido progresivo en el tiempo (esto es en función de las necesidades sentidas por el conjunto de la ciudadanía) y basado en el principio del mérito, y no en el reclutamiento repentino y partidario, tras ganar las últimas elecciones.

23 Por supuesto dentro de determinados límites aceptables y no superables. mantener sine die sus privilegios frente a las «mayorías naturales» generadas por la democracia-, el capitalismo moderado y la socialdemocracia han introducido en el siglo $x x^{24}$ ciertos límites a la acumulación de riqueza, como lo son: el impuesto progresivo sobre la renta de las personas físicas, los distintos impuestos anuales al capital (mobiliario e inmobiliario), y los impuestos progresivos sobre las herencias.

Debe subrayarse que tales limitaciones a la sobreacumulación del capital no solo no degradarán al capitalismo y a la democracia, sino que la fortalecerán, dotándola de un mayor grado de igualdad; valor este que, tras la correspondiente evaluación política parlamentaria, podría contar en democracia tanto como el derecho de propiedad.

Aún más, en la medida en que los ricos son siempre una minoría muy pequeña de la población de cualquier país (del 1 al 5 por 100 del total de votantes), y los menos favorecidos la mayoría; y en la medida en que la participación de los ricos en la renta y el capital tienda a concentrarse automáticamente -dada la dinámica subyacente del capitalismo-, la defensa «sin límites» de la propiedad privada resultará en definitiva una defensa de los ciudadanos más privilegiados. Por ello, tan solo una mezcla de propiedad privada, limitada por la existencia de impuestos progresivos y por la competencia entre los más acaudalados, permitirá alcanzar formas eficientes de capitalismo, combinadas con democracias sostenibles.

\section{Distribución personal de la renta y la riqueza: tendencias naturales, modelos teóricos de crecimiento y evidencia empírica}

La concentración progresiva e individual del ingreso y la riqueza es un tema que ha venido preocupando desde hace muchas décadas a filósofos y economistas. A esos efectos muchos $D$

$24 \mathrm{Y}$ aun antes. 
se han preguntado si K. Marx tenía razón cuando, a mediados del el siglo XIX, afirmaba categóricamente que las fuerzas sistemáticas del capitalismo llevarían inexorablemente hacia la concentración progresiva del capital; circunstancia que, a partir de un determinado momento, desencadenaría una revolución proletaria que desposeería a los capitalistas. $\mathrm{O}$ si, por el contrario, de acuerdo con lo sostenido por S. Kuznets ${ }^{25}$, la dinámica del crecimiento y la competencia introduciría a largo plazo una tendencia espontánea hacia la reducción de las desigualdades generadas en las primeras etapas del desarrollo de las naciones.

Inclinándose por una tercera vía, Piketty ha sugerido recientemente (2013) que el crecimiento moderno del siglo $x x$-apoyado en su segunda mitad por una expansión económica más acentuada ${ }^{26}$, y por una más rápida difusión del conocimiento y la tecnología- ha permitido evitar el apocalipsis previsto por Marx; pero no ha alterado la tendencia subyacente y automática del capitalismo, conducente a una desigualdad progresiva; lo que ciertamente contradice las tendencias convergentes sostenidas por Kuznets.

En relación con el análisis científico de la evolución temporal de la distribución personal de la renta y el capital en un contexto capitalista, Piketty sugiere que es absolutamente indispensable analizar los datos existentes sobre esas evoluciones en los 2 o 3 siglos pasados; y ello a fin de extraer ideas coherentes con la realidad, y no conclusiones erróneas derivadas de ciertas modelizaciones matemáticas basadas en supuestos irreales, o en la no consideración de fenómenos hoy relevantes (sociedades meritocráticas o reaparición intensa de las herencias).

Piketty subraya que, un análisis a largo plazo, con series referidas a los siglos XIX y XX, y a varios países, permite probar que la longitud de las series manejadas por Kuznets -defensor de la idea de la convergencia automática de las rentas personales- fue demasiado corta (periodo 1913-1948)

\footnotetext{
25 S. Kuznets fue Premio Nobel de Economía en 1971.

26 Sobre todo en el periodo 1950-1975.
}

como para justificar tal convergencia; y ello a pesar de que, de hecho y en ese periodo, se produjo esa tendencia convergente en EEUU. Consecuentemente, las tendencias «imaginadas» por Kuznets sobre la convergencia automática de la distribución personal de la renta (y del capital) no son, como todos hemos notado en las últimas décadas, de aplicación general en el tiempo y en el espacio.

Según Piketty, el análisis empírico de la evolución de la distribución personal de la renta y del capital en un contexto capitalista es relevante; pero no solo por razones conectadas con supuestas evoluciones naturales o automáticas de esos procesos (como las imaginadas por Marx o Kuznets) que han resultado falsadas por los hechos, sino también por la conveniencia de explicar las fluctuaciones observadas en esas evoluciones. Nótese que tras un periodo de desplome del capital y de sus rentas entre 1915 y 1945 (que afectó sobre todo a los más ricos), y tras la estabilización en la distribución personal de la renta y del capital, iniciada después de la Segunda Guerra Mundial, desde los años 1970-1980 en adelante, las desigualdades personales en renta y capital han vuelto a crecer fuertemente en los países industrializados.

En fin, las inesperadas fluctuaciones temporales del grado de concentración personal de la renta y la riqueza a nivel nacional, y la existencia de ciertos fenómenos laterales conectados ${ }^{27}$, fuerzan -según Piketty- a abandonar los modelos matemáticos de crecimiento ${ }^{28}$ ya conocidos, cuyas conclusiones estén desconectadas de la evidencia empírica. En particular y en un sentido innovador, Piketty introduce en el análisis de la $\triangle$

\footnotetext{
27 Como, por ejemplo, la importancia lateral de la evolución actual del crecimiento y de la distribución del capital y la renta en China, los efectos agregados en la distribución global de la evolución de los fondos manejados por los países productores de petróleo (singularmente Noruega) y por los fondos de pensiones globales, así como el crecimiento de los fondos manejados por los bancos con sede en paraísos fiscales.

28 Como sucede por ejemplo en el modelo neoclásico de Solow (sin progreso técnico), en el que, a largo plazo, todas las variables centrales (población total, población activa, y PIB) crecen al mismo ritmo, mientras la distribución del capital y del trabajo permanecen estables y constantes, si la elasticidad de sustitución es unitaria.
} 
evolución distributiva el tratamiento fiscal diferenciado (temporalmente) de los impuestos sobre la renta y las herencias, las distintas tasas de ahoro observables a lo largo del tiempo, y la tendencia reciente al crecimiento de las retribuciones de los altos ejecutivos de las grandes empresas; variables que han jugado históricamente un papel crucial y diferenciado, incrementando o reduciendo la concentración personal del capital y del ingreso.

\section{Resultados empíricos básicos obtenidos por Piketty}

Ciertamente, la historia de la, a veces, evolución (desconcentrada) en Occidente de la distribución personal de la riqueza y de la renta en el siglo $\mathrm{xx}$, ha sido durante largos periodos más bien la resultante de la evolución de los eventos acaecidos (guerras y crisis de 1929) y de la política económica aplicada -incluyendo el recrudecimiento de la progresividad impositiva en los principales países occidentales-, que de los puros automatismos inducidos por los mercados libres.

En sentido contrario, el crecimiento generalizado de la desigualdad distributiva, como la acaecida desde 1980 hasta hoy, ha tenido bastante que ver con el retorno a modos de fiscalidad previos: la implementación de reducciones de impuestos personales a los más ricos (IRPF) y la puesta en práctica por los Estados nacionales de políticas (competitivas) de reducción de las tarifas del Impuesto de Sociedades, inducidas por la introducción de la libertad de movimientos internacionales de capitales.

Aún más, en el mundo occidental actual también existen otras fuerzas adicionales tendentes a la divergencia (o concentración) de rentas y riquezas individuales, a las que Piketty ha dedicado una especial atención: 1) al proceso reciente, que comenzó con la Revolución Conservadora (1975-1980), proclive al alza de las retribuciones netas de los altos cargos (top executives) de las grandes empresas, vía reducciones del IRPF; 2) al proceso de acumulación de capital que, desde 1980, ha experimentado un cambio radical de dirección ${ }^{29}$, moviéndose de nuevo hacia posiciones más concentradas, semejantes a las que prevalecían hace un siglo, aunque menos concentradas en el último decil y últimos percentiles ${ }^{30}$; y 3 ) a la evolución de otras variables asociadas con la evolución de la relación capital/ingreso (b), como por ejemplo el crecimiento reciente del montante de los flujos sucesorios (herencias y donaciones) en términos de la renta nacional que, al incrementar la tasa privada de ahorro, han tendido a reforzar el crecimiento de la relación capital/ingreso ${ }^{31}$.

En definitiva, las conclusiones de Piketty apoyan la idea de una tendencia no monótona hacia el crecimiento de la relación capital/ingreso y hacia la concentración de la riqueza en todas las sociedades; pero la velocidad de ese crecimiento, de acuerdo con los datos disponibles, es mucho menos apocalíptica que la esperada por K. Marx. Y además, tal tendencia podrá ser revertida por los estados nacionales -ya lo fue en el siglo $x x-$ haciendo uso de instrumentos de política fiscal (impuestos progresivos).

29 Ese proceso de incremento de $b$ se ha debido tanto a los incrementos de la rentabilidad neta del capital $(r)$-inducidos, entre otras razones, por las reducciones de los impuestos a las rentas de capital- como por las reducciones observadas de la tasa de crecimiento, $(g)$.

30 En su metodología de análisis de la distribución personal del ingreso y de la riqueza, Piketty hace una opción metodológica relevante: descarta los índices sintéticos de concentración, como por ejemplo el índice de Gini, dado que, al sintetizar, estos índices esconden mucho más que lo que revelan; y en su lugar, hace uso intensivo de las diferentes porciones de renta o capital obtenidas o detentadas por los individuos pertenecientes a los diferentes deciles o percentiles (o décimas del último percentil) de cada sociedad. A esos efectos, Piketty divide grosso modo la sociedad en 3 clases claramente diferenciadas: 1) las llamadas clases populares, en las que incluye al 50 por 100 de la gente con menos renta o capital, grupo que normalmente acumula $u$ obtiene respectivamente cifras mucho menos importantes que ese 50 por 100, en torno al 5-10 por 100 del capital o al 30 por 100 de la renta; 2) las clases medias que incluyen al siguiente 40 por 100 con más renta o capital; y finalmente 3) el grupo de los ricos, posicionados en el último decil, grupo que, según países y épocas, acumula el 60 por 100 o más del capital y el 40 por 100 o más de la renta.

31 Nótese al respecto que aquellos que heredan, o reciben donaciones, tendrán ceteris paribus más facilidad para ahorrar que aquellos que no reciben flujos sucesorios, lo que facilita el incremento de la relación capital/ingreso e induce la aceleración de la participación de los capitalistas (a) en la renta nacional. 


\section{Las sencillas pero clarificadoras matemáticas de Piketty}

A fin de probar la tendencia subyacente del capitalismo hacia la concentración sistemática de la riqueza y de la renta personales, Piketty usa dos ecuaciones elementales ${ }^{32}$, bien conocidas por los economistas profesionales, a las que, enfáticamente, denomina «las dos leyes básicas del capitalismo»: [1] la relación $a=r b^{33}$, en la que a es la participación del capital en la renta nacional, $r$ es el rendimiento medio (neto de impuestos) pagado al capital por todos los conceptos (beneficios, intereses, dividendos, rentas de la propiedad, plusvalías, etcétera), y $b$ es la relación capital/ingreso o capital/producto; y [2] la relación $b=s / g$ en la que $s$ es la tasa de ahorro de la economía, y $g$ la tasa de crecimiento de la producción (del PIB), dependiente aditivamente de la tasa evolutiva de la población ocupada $(p o)^{34}$, y de la tasa de crecimiento de la productividad por persona ocupada $(p r)$.

La ecuación [2] es algo muy familiar para los economistas profesionales. Haciendo en esa ecuación [2] una trasposición sencilla, se llega a la expresión $g=s / b$, que es la condición de equilibrio del modelo Harrod-Domar, en su versión más simple de coeficientes fijos ${ }^{35}$; o la condición de equilibrio más general, relativa a los modelos de crecimiento con sustitución entre factores, en los que el valor de $b$ se transforma en variable (modelo neoclásico de crecimiento de Solow) al ajustarse automáticamente $b$, aunque a largo plazo, a los cambios habidos en $s$ y $g^{36}$.

\footnotetext{
32 Una de ellas es una mera identidad.

33 Nótese que la relación $a=r . b$ es una simple identidad, al ser $b$ la relación capital/producto o capital/ingreso.

34 En los modelos básicos de crecimiento, que no contemplan el paro como variable relevante, la tasa evolutiva de la población activa y de la ocupada coinciden. $Y$ en muchos de ellos, y por simplificar se hacen coincidir esas tasas evolutivas con la de la población.

35 Esta versión contiene el problema derivado de las diferentes velocidades de crecimiento de los factores. Diferencias de velocidades, que como veremos, tendrán una influencia sustancial en la distribución factorial de la renta (sobre todo en el siglo xxI) en función del valor de la «elasticidad de sustitución» entre factores.

36 Piketty, en función de sus objetivos analíticos, modifica el sentido de la causalidad del modelo de Solow.
}

Si ahora se introdujera la ecuación [2] en la [1], entonces se llegaría a la expresión [3]:

$$
a=r . b=r .(s /(g))=r .(s /(p o+p r))
$$

Teniendo ahora en cuenta que $r$ no puede ser nulo o negativo (eso no ha sucedido nunca en la historia económica reciente, salvo en el caso de guerras importantes extendidas temporalmente), resulta elemental deducir de la expresión [3] las variables que han tenido y tienen una gran influencia en el crecimiento del valor de $b$, y por tanto en el valor de $a$; o en el decrecimiento de (1-a). Nótese que (1-a) es la participación del trabajo en la renta nacional.

En efecto, es fácilmente deducible, en primer término, que si la tasa neta de rendimiento del capital $r$ se eleva, el valor de a (participación del capital en la renta nacional) tenderá a elevarse. Nótese que esa tasa neta de rendimiento $r$ se elevará: a) si se reducen los tipos marginales de los ricos en el Impuesto sobre la Renta de las Personas Físicas ${ }^{37}$, como ha sucedido desde el comienzo de la Revolución Conservadora (1980) en la mayor parte de países occidentales; b) si, al hilo del movimiento liberalizador internacional de capitales que empezó en los años 1980 y 1990, se desarrolla un movimiento pro-competitivo (a la baja) entre los distintos Estados nacionales en relación con la tarifa impositiva del Impuesto de Sociedades, a fin de atraer capitales extranjeros; y c) si se producen, como ciertamente ocurre, economías de escala en la gestión de las inversiones financieras, lo que implica que, cuanto mayor es el tamaño del capital o cartera gestionados, menores serán sus costes administrativos, y mayor será el tipo de rendimiento neto obtenido $r$.

Continuando con el análisis de la expresión [3], Piketty nos recuerda, de un lado el menor ritmo evolutivo actual de la población ocupada en $\triangleright$

$37 \mathrm{O}$ si se reducen los tipos que giran sobre los rendimientos del capital, que básicamente afectan a los ricos. Esto es lo que ha ocurrido desde 1980, en tiempos de las iniciativas fiscales de ThatcherReagan, seguidas de otras variaciones posteriores similares, promovidas por otros dirigentes como Bush Jr. 
Occidente, derivado de las tendencias demográficas corrientes, con ritmos de crecimiento ya muy bajos; y de otro, la tendencia histórica de la evolución de la productividad del trabajo que, tras haberse movido durante siglos sobre tasas evolutivas del 0,5-1 por 100, solo rebasó esas cifras en el periodo de la Reconstrucción Europea, 1945-1975.

Por fin, la relación capital/ingreso también crecerá si crece la tasa de ahorro $s$ de la sociedad (esto es, si crece la relación entre el ahorro nacional y la renta nacional). Y eso ocurrirá si se produce ceteris paribus una elevación de los flujos sucesorios netos privados transmitidos generacionalmente (herencias y donaciones), lo que ocurrirá en función de: 1) la reducción de la progresividad en los impuestos sobre las herencias y donaciones, lo que ya ha sucedido prácticamente en todo Occidente; 2) el alargamiento de la vida esperada, lo que incrementará -aunque retardará- el volumen de los importes heredados; y 3) la reducción del número de hijos por familia, lo que ceteris paribus, incrementará el volumen del capital per cápita hereda$\mathrm{do}^{38}$, variación que conducirá a posteriori, a una elevación de $s$ de los más ricos.

\section{El diferencial $r-g$ como determinante básico de la tendencia del capitalismo hacia la concentración de riqueza y renta}

Como ya se ha señalado, la dinámica de la economía de mercado -aun cuando ésta se comporte de modo perfectamente competitivo- siempre contendrá algunas fuerzas divergentes ciertamente devastadoras, que si los Estados (o el sector público) no controlaran, podrían constituirse en el futuro en una amenaza potencial a la sostenibilidad de las sociedades democráticas.

Claramente, y ocurra lo que ocurra con las fuerzas propensas a la convergencia (inversión en educación, difusión del conocimiento, etcétera),

\footnotetext{
38 Por quienes hereden. Nótese que la mitad de la población en Occidente no hereda prácticamente nada.
}

la fuerza divergente más potente y desestabilizadora del capitalismo es el valor, casi siempre positivo del diferencial $r-g$. En efecto, cuando el diferencial $r-g^{39}$ sea positivo, ocurrirá que la riqueza acumulada por los individuos crecerá de modo más rápido -por ejemplo a un ritmo medio real calculado de $r$ del 4-5 por 100- que el ritmo evolutivo anual $g$ de la producción y los salarios (que normalmente no será mayor que el 2-2,5 por 100), lo que inducirá una acumulación del capital a una tasa mayor que el crecimiento de la producción. En palabras de Piketty, «el pasado tiende a devorar el futuro", y las rentas pagadas a los capitalistas -titulares mayoritarios de toda la acumulación acaecida en el pasado- podría perjudicar sistemáticamente a la mayoría de la población, casi carente de capital, esto es de rentas ajenas a su trabajo personal.

Por consiguiente, en ausencia de shocks económicos adversos (guerras o grandes crisis económicas, como las ocurridas en la primera mitad del siglo $x x$ ), la resolución del problema de esa progresiva concentración del capital y de la renta, no admitirá políticas sencillas que no requieran de esfuerzos relevantes. Antes al contrario, la resolución del problema distributivo requerirá de los Gobiernos posicionamientos políticos contrarios a la concentración de la renta y la riqueza. Ciertamente -subraya Piketty- la tasa de crecimiento de la economía, $g$, puede ser estimulada con inversiones en educación, conocimiento, etcétera; pero eso no hará que en el futuro el valor de $g$ sea fácilmente incrementable hasta niveles del 4-5 por 100, que es la tasa anual requerida para evitar la tendencia automática a la concentración de los capitales.

Nótese que los países actualmente pioneros en tecnología -como EEUU o algunos países europeos- no rebasarán fácilmente en el futuro tasas medias de crecimiento anual del 1,5-2 por $100^{40}$. $D$

39 Nótese que en el modelo de crecimiento neoclásico sin progreso técnico se generará un óptimo (regla de oro de Phelps) cuando el rendimiento real del capital $r$ se iguale a la tasa de crecimiento real g. Pero eso sucederá solo a muy largo plazo. Ahora bien antes de alcanzarse ese óptimo, la sostenibilidad político-social del proceso (con $r$ casi siempre mayor que $g$ ) podría transformarse en imposible.

40 Piketty sugiere tasas aun menores, como del 1-1,5 por 100. 
Por consiguiente, es altamente probable que, ceteris paribus, el diferencial $r-g$ continúe siendo positivo a lo largo del siglo XXI, y que el capital continúe con su proceso de expansión y concentración, como ha ocurrido la mayoría de las veces en la historia conocida.

\subsection{Evolución de la participación del capital (a) en el siglo $x x$}

Al igual que la evolución gráfica de $b$ ha adoptado temporalmente una forma de $U$ en el periodo $1910-2010^{41}$, la participación del capital en el PIB también ha adoptado un aspecto similar, falsando así respectivamente las conclusiones de divergencia «sostenida» 0 de convergencia a largo plazo, de Marx o Kuznets. Obsérvese que el valor de la participación del capital (a) en la producción fue del orden del 35-40 por 100 en Francia y el RU a finales del siglo XIX. Años más tarde, a mediados del siglo $\mathrm{xx}$, esa participación cayó hasta el 20-25 por 100, debido a los grandes shocks de la época, para crecer de nuevo hasta el 25-30 por 100 a finales del siglo xx y principios del XXI. Nótese que las anteriores cifras relativas a la participación del capital en la producción derivan no solo de la evolución de $b$ sino también del rendimiento neto medio del capital invertido $(r)$, de en torno al 5-6 por 100 a lo largo del siglo XIX y principios del $x x$; tasa que se movió hasta el 7-8 por 100 a mediados del siglo $x x$, para finalmente caer hasta cifras del 4-5 por 100, en los últimos años del siglo $x x$ y primeros del $x X I$.

De cara al futuro, Piketty cree que ese rendimiento neto $r$ se elevará en la primera mitad del siglo XXI, a partir de la progresiva reducción de los impuestos sobre el capital en los diferentes países occidentales, y de la creciente sofisticación en la administración financiera de grandes carteras (como las de los fondos petrolíferos, fondos de pensiones gigantes, fondos nacionales, grandes

\footnotetext{
41 Según lo descrito gráficamente por Piketty, en su libro ya mencionado, de 2013.
}

reservas internacionales de países como China, etcétera).

\subsection{El papel de la elasticidad de sustitución en la distribución (capital-trabajo) del ingreso en el siglo $x x I$}

En relación con las futuras tendencias de los valores netos de $b$ y de $a$, en el contexto del capitalismo global, Piketty dedica una atención especial al valor de la elasticidad de sustitución de los factores, capital y trabajo. Es bien sabido que a partir de la ley de las productividades marginales decrecientes, un crecimiento del capital más rápido que el del trabajo provocará una reducción de su rendimiento relativo $(r) \mathrm{y}$, ocasionalmente, una reducción de su participación en la producción (reducción de a). Pero esto último solo sucederá cuando el valor de la elasticidad de sustitución sea menor que la unidad. Contrariamente, si la elasticidad de sustitución entre factores fuera mayor que la unidad (lo que es probable que ocurra en el siglo XXI, según Piketty), eso conduciría a que si $b$ tendiera a crecer en el siglo XXI-como ya lo hace hoy- a también crecería.

A este respecto Piketti sugiere que en un futuro próximo, la elasticidad de sustitución entre capital y trabajo estará comprendida entre el 1,3-1,6 (no siendo unitaria, como se supuso durante gran parte del siglo $x x)^{42}$. Y es que, por ejemplo, el equipo doméstico de los apartamentos en las ciudades, los equipos electrónicos y robóticos en las empresas, o las tecnologías intensivas en capital usadas en los análisis y en los tratamientos médicos, tienden a producir crecimientos de la participación del capital, aunque se reduzca el rendimiento marginal por euro invertido en ese factor. Todo apunta, por tanto, a que si la evolución de la intensidad del capital $b$ continuara creciendo (debido a que el valor de $g^{43}$ puede tender a $\triangleright$

\footnotetext{
42 Elasticidad de sustitución unitaria que solo sucede cuando se usan funciones de producción Cobb-Douglas.

${ }_{43}$ Recordemos que $g$ es la tasa de crecimiento anual de la producción, equivalente a la suma de las tasas de crecimiento de la población ocupada, y de su productividad.
} 
reducirse en las próximas décadas, y el de $s$ a aumentar), la participación del capital, $a$, tenderá a crecer en el mundo, al igual que ha venido sucediendo en términos de medias en el periodo 1975-2010, en EEUU, Alemania, RU, Canadá, Japón, Francia, Italia y Australia.

Una conclusión lateral de lo anterior es que si la elasticidad de sustitución entre factores fuera mayor que la unidad, y $b$ creciera deprisa-como bien podría suceder en el siglo XXI-, la idea de que el capital humano y el «principio del mérito» podrían conducir a participaciones crecientes del trabajo, podría no ser más que una simple ilusión.

Así pues, la conclusión final de Piketty es que si $g$ entrara en un estadio de crecimiento lento, esa vuelta a tasas bajas de crecimiento productivo conducirá a crecimientos de la intensidad de capital $b$; paralelamente, si en las semiestancadas sociedades occidentales futuras, la elasticidad de sustitución entre factores fuera mayor que la unidad, el capital de los capitalistas y su participación en la producción ganarían importancia relativa. Contrariamente, si la elasticidad de sustitución fuera menor que la unidad, incrementos de $b$ forzarían un incremento de la participación del trabajo en la producción-ingreso, sin embargo, de acuerdo con Piketty, parece poco probable.

Así pues, analizando todos los datos relevantes, puede concluirse que, en relación con la intensificación de la capitalización y la concentración de la distribución de la renta, no hay «fuerzas naturales» que permitan reducir la actual importancia creciente del capital (b) y su participación en la renta nacional $(a)^{44}$. En sentido contrario, hay argumentos políticos suficientes (uso de la política fiscal) que han determinado ya en el pasado la evolución oscilante del valor de $b$ y la «fluctuante» retribución a los capitalistas a lo largo del siglo $x x$.

\footnotetext{
44 Ciertamente, sugiere Piketty, ni la tecnología ni los mercados conocen límites morales; razones por las que carece de sentido esperar que la evolución de la tecnología o el fomento de la competencia nos conduzcan a un orden moral más justo.
}

\section{La concentración de los salarios y del capital. Evolución y rasgos más importantes}

Hasta ahora se ha analizado, aunque de modo agregado, la distribución del ingreso entre capital y trabajo, y sus tendencias a largo plazo, pero no se han analizado en detalle las desigualdades internas en lo que se refiere a los ingresos totales del capital, o del trabajo, aspectos sumamente ilustrativos. Nótese al respecto que la distribución total de los ingresos-rentas en un determinado país, dependerá: 1) de la desigual distribución de los salarios; 2) de las desiguales retribuciones al capital; y 3) de las relaciones -vía ahorro- entre esas dos dimensiones del fenómeno distributivo.

Aunque la superioridad de los capitalistas en el campo de la distribución era ya aplastante y tremendamente injusta en el siglo XIX, la distribución interna actual de los salarios percibidos por los trabajadores también es bastante injusta. En efecto, aunque a mediados del siglo xx (1950-1975) la situación distributiva personal conjunta se transformó en más justa, en las últimas tres décadas del siglo xx y comienzos del siglo xxI la situación distributiva se ha movido (y se está moviendo) en dirección opuesta, básicamente por dos razones: 1) por el crecimiento de $b$ favorable a los capitalistas, en paralelo con la existencia de una elasticidad de sustitución mayor que la unidad; y 2) por la aparición de retribuciones salariales extremadamente exageradas a los altos ejecutivos, lo que ha perjudicado adicionalmente a la mayoría de los trabajadores pertenecientes a las clases media y popular.

Según la teoría económica convencional, la desigualdad en cuanto a la distribución de los salarios ha tenido que ver básicamente, y en cada momento histórico, con la calidad del sistema educativo de las naciones, con los distintos grados educativos alcanzados individualmente, y con las normas que regulan el mercado laboral. Por su lado, las rentas de capital han tenido y tienen muy diferentes orígenes y causas, dependiendo estas $\triangleright$ 
de: 1) las tasas de ahorro e inversión previas; 2) la normativa fiscal sobre los flujos sucesorios de riqueza (esto es donaciones y sucesiones); y 3) la evolución de los mercados financieros.

Ciertamente, la acumulación sostenida del capital se debe a que los capitalistas tienen algunas razones para acumular que, en ocasiones, escapan a la lógica económica convencional. Algunos acumulan un capital excesivo por precaución, otros lo hacen para tener una pensión aceptable cuando les llegue la jubilación (hipótesis del ciclo vital de Modigliani); y otros acumulan capital simplemente por prestigio social; actuaciones que en su conjunto no hacen sino desplazar hacia el futuro las desigualdades actuales; desigualdades que, además, tienden a crecer casi automáticamente, dado que $r$ es mayor que $g$.

En relación con la distribución interna de los ingresos de los trabajadores, Piketty sugiere que el 10 por 100 más afortunado (de los trabajadores) en los distintos países analizados, obtiene actualmente entre el 20 y el 35 por 100 de los ingresos de todos los asalariados. Concretamente, en torno al 20 por 100 del total en los países nórdicos, el 25 por 100 en la UE, y el 35 por 100 (por la fuerte desigualdad salarial existente) en EEUU. Y ello mientras esa desigualdad salarial está tendiendo a acentuarse, sobre todo en EEUU. Contrariamente, el 50 por 100 de trabajadores con menores ingresos (las llamadas «clases populares») reciben respectivamente en esos países el 35, 30, y 25 por 100.

Continuando con esa clasificación de países, y hablando ahora de la distribución de la propiedad del capital, el 10 por 100 más rico posee hoy en esos grupos de países, respectivamente un 60 , un 60 , y un 70 por 100 del total. Y ello mientras el 50 por 100 más pobre posee respectivamente alrededor del 25, el 10, y el 5 por 100; quedando el resto 15,30 y 25 por 100 para las clases medias.

Volviendo al campo de los ingresos laborales, es particularmente interesante la tendencia observada en EEUU a lo largo de las últimas décadas, de pagos crecientes a los superejecutivos; tendencia que si se mantuviese, podría llevar a
EEUU en 15-20 años a que el 50 por 100 de los asalariados peor pagados obtuviera tan solo el 10-15 por 100 de los salarios totales mientras el 10 por 100 de trabajadores mejor pagados se quedaría con casi la mitad del pastel salarial.

\subsection{La aparición de las sociedades meritocráticas. ¿Causa de la crisis financiera de 2008?}

Ha de insistirse que en las últimas tres décadas ha aparecido una nueva forma de sociedad, surgida inicialmente en EEUU, basada en lo que incorrectamente se denomina «hipermeritocracia»; sociedades estas en las que las superestrellas de cualquier actividad o los superejecutivos dominan el escenario distributivo. Se trata de sociedades sumamente desiguales en las que los estratos más altos del ingreso están dominados más por los altísimos salarios de unos pocos que por las herencias; justo lo contrario a lo que sucedía en tiempos de la Belle Époque en Francia, RU, y EEUU. En esas sociedades hipermeritocráticas es fácil imaginar cómo los superejecutivos (actuales) pueden transformarse en pocos años en rentistas (capitalistas) por la vía de la acumulación de sus superahorros, provenientes de sus excesivos e injustificados ${ }^{45}$ salarios. Por supuesto que sus descendientes, ya en segunda generación, se transformarán en puros rentistas, o en rentistas que también trabajan.

Debe hacerse notar que, en el siglo xx, la composición del total de las rentas (provengan estas del trabajo o del capital) del grupo de los más ricos $D$

\footnotetext{
45 En la discusión sobre la injustificabilidad de esos salarios, entran en juego conceptos como los del inaplicable principio de la productividad marginal a las labores no sistemáticas realizadas por esos individuos, a la falta de proporcionalidad de sus ingresos con sus presuntamente altísimos capitales humanos (algo totalmente irreal por comparación a los de los colegas que les rodean), etcétera. Esos salarios se deben básicamente a la globalización y al mayor tamaño de sus empresas, al hecho de que los consejos de administración -de los que forman parte los superejecutivos- son los que dictan los supersalarios, y a la progresiva reducción de los tramos más altos del IRPF, que ahora permiten pagar salarios netos mucho mayores, sin un esfuerzo empresarial apreciable.
} 
ha cambiado significativamente en los países europeos, y también en EEUU. Y lo ha hecho como consecuencia: 1) de las dos guerras en las que estuvieron implicadas Francia y Alemania, lo que generó importantes destrucciones de activos, en general propiedad de los ricos rentistas de principios del siglo xx; 2) de las quiebras (que también afectaron básicamente a los ricos) resultantes de la crisis económica que se inició en 1929; 3) de la práctica de la eutanasia de los rentistas, de resultas de la gran inflación que los Gobiernos de Alemania y Francia generaron para pagar la deuda pública originada por esas dos guerras; y 4) de la reorganización del Impuesto sobre la Renta de las Personas Físicas, fuertemente incrementado (en Francia, EEUU y otros países) a partir de 1914.

Como consecuencia de la menor relevancia de los capitalistas-herederos hasta los años setentaochenta del siglo xx, y de la progresión de la hipermeritocracia a partir de los ochenta, las rentas de capital no sobrepasan ya a las de los hiperasalariados más que en el último percentil (el del 1 por 100 más rico). Esto significa que los capitalistas puros son hoy mucho menos numerosos y poderosos que antaño. $Y$ dado que el grupo humano del 10 por 100 con mayores ingresos siempre ha asumido el liderazgo social, las sociedades occidentales han mutado desde unas sociedades controladas básicamente por los capitalistas-rentistas, a otras controladas por los superejecutivos, que hoy son mayoría en el último decil (10 por 100 más rico).

En lo concerniente a EEUU es perceptible que, en relación con el grupo del 10 por 100 más rico, este decil, tras permanecer en el 30-35 por 100 del total de ingresos (de capital o trabajo) en el periodo 1945-1980, se ha movido en las últimas tres décadas hasta el 45 por 100 o más (casi el 50 por 100) en 2010; lo que supone un alza importante de rentas derivado de la elevación de los ingresos de los superejecutivos; y, también, de la reaparición (todavía solo parcial) de la importancia de las herencias, fenómenos que en su conjunto han producido en EEUU una sociedad mucho más desigual que la de mediados del siglo $\mathrm{xx}, \mathrm{y}$ también mucho más desigual que las sociedades europeas actuales.

Como consecuencia de la crisis de 1929 y del intenso shock fiscal introducido por Roosevelt contra los ingresos elevados, y tras la Segunda Guerra Mundial, EEUU también experimentó -al igual que los países occidentales europeos- una compresión de las desigualdades, lo que hizo que el 10 por 100 más rico volviera a recibir solo el 30-35 por 100 del total de rentas. Ahora bien, desde la década de 1970-1980, las desigualdades de ingresos en EEUU han experimentado una explosión sin precedentes, alcanzando el grupo del 10 por 100 más rico, como se ha dicho, el 45-50 por 100 de la renta nacional en el periodo 2000-2010, lo que implica un crecimiento de 15 puntos en su participación en esa renta nacional. Ciertamente, un incremento excesivo que lleva a preguntarnos si ese crecimiento podrá continuar o no en el futuro, y si ese 10 por 100 más rico podrá acercarse o no, en 2030, a recibir el 60 por 100 de la renta nacional.

Dicho eso, uno también debería preguntarse si la crisis financiera iniciada en 2008 en EEUU ha sido la causa de la desigualdad creciente en ese país, o si, contrariamente, la desigualdad creciente ha inducido, al menos parcialmente, la cri$\mathrm{sis}^{46}$. Piketty sugiere que el cuasi estancamiento de los ingresos de las clases populares desde 1970 hasta hoy (con un crecimiento anual real medio de menos del 0,5 por 100), significa que en las décadas mencionadas se ha producido una transferencia de 15 puntos porcentuales desde el 90 por 100 de individuos con menores ingresos individuales (clases media y popular) al 10 por 100 más rico. Transferencia interna 4 veces más importante que la realizada al extranjero (a China, Alemania, etcétera), como consecuencia del déficit comercial acumulado por EEUU a lo $\triangleright$

46 Según podría deducirse de los supuestos contenidos en el modelo keynesiano de Kaldor. Así, si los ricos hubieran ahorrado mucho, su menor propensión media al consumo habría redundado en una menor demanda agregada y en una menor producción. Véase al respecto cualquier manual de Macroeconomía. 
largo de los años 2000 que, en ocasiones, ha sido considerada como la causa de la desestabilización progresiva (anterior a 2008) del sistema financiero de los EEUU. Por consiguiente, según sugiere Piketty, el desigual crecimiento de los ingresos y la superconcentración de estos podrían haber sido algunas de las causas más importantes de la catástrofe económica iniciada en 2008 en EEUU.

\section{La importancia de las herencias en el siglo XXI y mezcla de ingresos de los más ricos}

Además de la influencia determinante de $r$ y $g$, sobre $b$ y $a$, hay otras variables, aún no consideradas, que también actuarán, aunque en menor medida, sobre la distribución interna del capital privado (propiedad y rendimientos). Se trata de: 1 ) las herencias y donaciones; 2) la importancia del ahorro en la formación de la riqueza a lo largo de la vida de los individuos; y 3 ) la esperanza de vida, que incrementa por sí misma el valor de las herencias trasmitidas a los herederos, mientras ralentiza el proceso hereditario a corto-medio plazo.

Obviamente si, como sucede en general, $r$ es mayor que $g$, el fenómeno de las herencias será inevitable. Esto significa que las desigualdades formadas y acentuadas en el pasado reciente (19702010), que finalmente desembocarán en herencias, tendrán una influencia significativa y duradera en el futuro. En efecto, dadas las tendencias recientes de ry g, ya comentadas, la evolución de b será creciente y por consiguiente, las herencias (y/o las donaciones) adquirirán en Occidente, y quizá en todo el planeta, una importancia similar a la que ya tuvieron en el siglo xIx en Europa y EEUU. Fenómeno que probablemente será completado con los ahorros incrementados de los superejecutivos, lo que producirá en las siguientes generaciones una diferente mezcla de rentas (de la propiedad) y salarios.

Para analizar el problema de las herencias y sus determinantes, es importante definir el «importe anual del flujo sucesorio» como la suma transferida vía herencias y donaciones en un país a lo largo de un año, en términos de su propia renta nacional. Analizando el caso de Francia, Piketty extrae reglas aplicables a cualquier país del mundo. Específicamente, y en relación con la evolución de las sucesiones en el país galo en el periodo 18202010, dos datos emergen con claridad: 1) que el flujo sucesorio anual representó a lo largo del siglo XIX un valor anual de alrededor del 20-25 por 100 de la renta nacional, con una ligera tendencia al crecimiento a finales de siglo; y 2) que ese flujo sucesorio se colapsó en el periodo 1910-1950, alcanzando niveles del 4 por 100 de la renta nacional, para recuperar posteriormente (2010) niveles del 15 por 100.

Nótese que la caída de los flujos sucesorios en el periodo 1914-1945 fue el doble de fuerte que la caída de los patrimonios privados en el periodo. Esto significa que la importancia de las herencias y las donaciones fue mucho menos relevante en ese periodo que en el siglo XIX, y que la acumulación acaecida entre 1914 y 1945 se hizo más bien trabajando y ahorrando, que heredando. De cara al futuro, Piketty, analizando dos opciones estimatorias y de acuerdo con la opción menos favorable a los herederos, sugiere que los flujos sucesorios continuarán creciendo hasta 2030-2040 para alcanzar finalmente un nivel estable del 16-17 por 100 de la renta nacional. En el escenario alternativo, la progresión de los flujos sucesorios sería más intensa, llegándose en 2060 a tasas del 24-25 por 100, es decir, a un nivel similar al de finales del siglo XIX.

Con los datos conocidos sobre los flujos sucesorios, Piketty ha construido una relación entre los flujos sucesorios totales y la riqueza acumulada en Francia, llegando a las siguientes conclusiones: 1) que en el siglo XIX, cuando los flujos sucesorios representaban anualmente un 20-25 por 100 de la renta nacional de Francia, la riqueza heredada era entorno al 80-90 por 100 de la riqueza privada total, lo que significa que la mayor parte de los capitales existentes eran heredados $^{47}$; algo coherente con el hecho de que, entonces, solo una minoría de personas que había $\triangleright$

\footnotetext{
47 La acumulación de ahorro procedente del trabajo era muy escasa en el siglo XIX, al ser pobre la mayor parte de la población y pequeño el ritmo de crecimiento $g$ de entonces, debido a los bajísimos incrementos de la productividad del trabajo ocupado y al limitado ritmo del crecimiento de la población.
} 
empezado de la nada y reunía una cantidad significativa de capital a lo largo de su vida; 2 ) que tras el colapso de los capitales (b) desde 1910 en adelante, el capital recibido en herencia comenzó a decrecer en términos del capital privado total, hasta alcanzar su punto más bajo en 1970, representando en ese año tan solo el 40 por 100 del capital privado total, lo que significa que por primera vez en la historia (de Francia) la mayor parte del capital detentado por los individuos no había sido heredado. Sin embargo, desde entonces, la proporción del capital heredado no ha parado de crecer, representando ya en 2010 un 70 por 100 del capital privado total, siendo posible que ese capital heredado alcance en 2030-2040 una cifra aproximada al 80 por 100 .

De otro lado, al describir la mezcla actual de ingresos de los más ricos ${ }^{48}$, Piketty señala que las sociedades occidentales y democráticas (actuales) no han sido capaces de incrementar en las últimas décadas la participación de los salarios en la renta nacional (1-a). En lugar de eso, lo que ha ocurrido es que además de incrementarse la participación del capital en la producción total, se ha producido un proceso de sustitución -por supuesto favorable a los superejecutivos- de unos asalariados por otros, dentro del total de salarios; sustitución, que los altos ejecutivos han usado para acceder a los rangos más altos de ingresos de la sociedad en su conjunto. Todo lo anterior indica que la largamente esperada movilidad intergeneracional, supuestamente inducida por las inversiones reforzadas en educación y conocimientos (capital humano), lamentablemente, no han surtido los efectos distributivos esperados ${ }^{49}$.

Resumiendo, podría decirse que el volumen relativo de los flujos sucesorios anuales y del capital acumulado no solo está creciendo en la actualidad,

48 En el grupo de los más ricos pueden encontrarse hoy algunos rentistas, que también tienen títulos o grados profesionales, que no implica necesariamente que sus ganancias obtenidas trabajando hayan crecido significativamente. De otro lado, los superejecutivos, con sus exagerados ingresos, pueden ahorrar e invertir significativamente, entrando así automáticamente en la categoría de rentistas.

49 Esas inversiones reforzadas en educación solo han desplazado hacia arriba, y en paralelo, el nivel medio de conocimientos, lo que no ha inducido la convergencia de rentas. sino que además está tendiendo a recuperar los niveles de finales del siglo XIX; aunque ciertamente hoy quedan menos superrentistas mientras, al tiempo, ha aparecido una nueva clase patrimonial ${ }^{50}$ que ha accedido a una significativa participación en la propiedad.

\section{Correcciones fiscales a las tendencias subyacentes del capitalismo}

Habida cuenta de las consideraciones anteriores derivadas de los datos históricos disponibles, si los Estados quieren evitar en el futuro el dominio económico, y a veces político, de los más ricos, será preciso introducir políticas fiscales específicas y discriminatorias que permitan limitar, dentro del sistema capitalista, la indefinida propensión a la concentración del capital, inducida por el diferencial positivo o creciente $r-g$, que ha reaparecido con gran virulencia en los últimos 30 años (1980-2010).

De acuerdo con Piketty, el mejor instrumento disponible para detener esa tendencia a la concentración del capital y de la renta -desestabilizadora por sí misma de la paz social y la democracia-es el establecimiento (en el futuro) de una importante y progresiva (aunque no confiscatoria) imposición anual sobre el capital ${ }^{51}$; y ello a fin de reducir la capacidad del capital para autoreproducirse a tasas $r$ muy superiores al valor de $g$. Pero nótese que la instrumentación de tal impuesto deberá hacerse cuidadosamente, ya que de otro modo, la inversión agregada podría tender a decrecer y la tasa de crecimiento a reducirse, lo que ciertamente sería contraproducente a efectos de evitar la concentración del capital y del ingreso.

50 Compuesta por los superejecutivos y últimos percentiles de la clase media.

51 Una imposición anual y progresiva sobre el capital privado (neto de deudas) existente, y una más progresiva imposición sobre el capital heredado (lo que viene a producirse solo cada 30 años, cada generación), complementarían la actualmente agotada progresividad en la imposición sobre la renta de las personas físicas que, en la práctica, ya no es pagada por los ricos, dado su alto nivel de ingresos no sujetos de hecho al impuesto. 
Así pues, el establecimiento de ese impuesto anual y progresivo sobre el capital ${ }^{52}$ sería una solución aceptable para desactivar la actual «espiral de desigualdad», haciendo a la vez posible el mantenimiento de un deseable esquema económico competitivo, que de otro modo (sin el mencionado impuesto) sería sustituido por un sistema progresivamente monopolístico ${ }^{53}$, contrario a los intereses de la sociedad.

Ahora bien, la dificultad básica para el desarrollo de esa estrategia de imposición anual y progresiva sobre el capital individual es que tal estrategia requiere de un grado de cooperación y transparencia internacionales en lo financiero $y / 0$ de una integración política regional ${ }^{54}$, que aún no

\footnotetext{
52 Véase Piketty, T. (2013), libro ya mencionado. En ese libro su autor sugiere a titulo orientativo que la tarifa progresiva en el impuesto anual sobre el capital podría ser: del 0,1 al 0,5 por 100 para capitales acumulados hasta 1 millón de euros; del 1 por 100 entre 1 y 5 millones de euros; del 2 por 100 entre 5 y 10 millones de euros; y del 5 al 10 por 100 para fortunas superiores a los cien millones de euros.

$53 \mathrm{O}$ por otras fuerzas o estructuras políticas que podrían finalmente capturar a los Gobiernos, lo que podría desactivar los valores positivos de la democracia.

54 Que crean sistemas automáticos de transmisión de información financiera entre los distintos países.
}

ha sido alcanzada ni siquiera por los Estados europeos actuales, que desafortunadamente funcionan con «constituciones políticas» aún no adaptadas a la globalización del mundo actual ${ }^{55}$. Nótese al respecto que en la Unión Europea, la construcción del mercado único -que desde 1986, ha tratado de incrementar la competencia- ha podido conducir a elevar el diferencial $r$-g, lo que ceteris paribus ha podido incrementar la concentración del capital. Concentración que no proviene de las imperfecciones del mercado -contra las que la UE lucha- sino del bajo crecimiento de la producción y de los salarios, resultantes ambos de la competencia internacional. Consecuentemente, en un contexto global y sin fronteras, Piketty cree que no hay mejor opción que el establecimiento de un impuesto anual y progresivo sobre el capital, a fin de defender la democracia y su supervivencia a largo plazo.

\footnotetext{
55 Particularmente, en el caso de los países europeos pequeños, tan solo una completa integración de las políticas regionales, en particular el establecimiento de «un sistema automático de transparencia financiera» podría ayudar a construir una regulación fiscal sobre el capital que ayudara a detener el crecimiento de la concentración de la riqueza.
} 